\title{
Catering for different learning styles
}

\author{
Manfred Kwok and Clifford Jones
}

European Business Management School, University of Wales, Swansea

This paper describes a study to investigate the possibility of applying a quick and simple front-end to multimedia presentations. The front-end will determine the user's learning style and suggest a suitable navigation method. The paper recognizes not only different learning styles which influence learners' performance, but also the practical use of valid learning styles' measurements.

\section{Introduction}

The use of computers for teaching and training has long been a controversial issue. Up to the 1980s, many educators who were keen to use computers to pass on knowledge developed various computer-based teaching and training materials, but most of these materials were capable only of delivering information in text with perhaps some computer graphics, and in many cases it proved difficult to raise learners' interest in the subject matters (Patrick \& Fitzgibbon, 1988). In the 1990s, there has been cheerful news for procomputer educators; the latest multimedia technology could be the solution to the problem. Using a multimedia personal computer we can retrieve information in diverse formats: text, high-quality audio, still and animated graphics, and still and moving pictures.

However, to understand how to teach people effectively with computers, it is first necessary to find out what people want and what they expect from computer teaching and training materials. It would be foolhardy to produce a computer teaching/training program and expect all users to learn things equally well. In fact, much past research has shown that people have different learning styles, and one's learning style is built up by many different past experiences (Entwistle, 1987). Computer experience, and how the user feels before and during looking at computerized material, may also affect learning style, and hence interactions with the computer.

Ideally, every computerized teaching/training program should have many versions in the 
presentation of information, covering all users' learning styles, computer experience, mood, etc. For example, one version may be a straightforward presentation, another version may be fully interactive.

\section{The problem of catering for different learning styles}

\section{Learning styles}

If we all accept the level of interactivity as being a key factor which affects how well and how much learners learn from programmed materials, the immediate problems are to identify what factors may affect learners' study styles, and to find out how to provide optimal computer interaction.

The notion of cognitive styles gained recognition in the 1950s and 1960 s as a significant personal characteristic which raised the understanding of how people learn. Cognitive style has been variously defined (Kogan, 1971; Messick, 1976). However the authors here would define the term as the unique and preferred way in which an individual processes, stores and retrieves information. Study strategies are simply cognitive styles applied when individuals go about learning. Messick defined as many as nine distinctive dimensions (Messick, 1970). Witkin's work on two different cognitive styles, called field-dependent and field-independent, showed the differences in the way an individual structures and analyses information (Witkin, 1976). Pask and Scott (1972) and Pask (1976) distinguished two distinctive styles of learning, identified as holist and serialist strategies. Marton \& Säljö (1976) identified two study approaches: deep approach and surface approach. Kolb (1984) defined four learning styles: accommodation, assimilation, divergence, and convergence. All this produces a confusing picture of different learning styles, strategies and approaches. Clarke (1993) (together with the authors of this paper) suggests bravely that these styles 'differ more in name than nature' and that they 'can be classified into either a preference for a reasonable degree of structure and guidance [serial] ... or a preference for considerable freedom to explore [holistic]'.

\section{Learning styles measurement}

One problem is to find out users' learning styles. Some learning-style test procedures, inventories and questionnaires have been suggested for determining learning styles effectively and sufficiently, but these tests and questionnaires are mostly very timeconsuming to complete and/or they may require instructors to assess their outcomes (Pask, 1973; Kolb, 1984; Weinstein et al., 1983). It would be highly impractical, perhaps somewhat cruel, to ask users first to spend considerable time completing those tests or questionnaires before using any computerized programs. What we want is a quick and easy, reliable and valid measure of style which occurs as an immediate prerequisite to involvement in the program, such that users can determine their own learning strategy and preferred navigation method within the system. A well-designed multimedia system, together with opportunities for multiple navigational strategies provided by a range of navigational methods, will encourage users to adopt a 'best method' to suit their individual study strategy. We will call such an approach to programs and presentations: front-end applied programs or front-end applied presentations. 


\section{Experimental study with front-end applied multimedia presentations}

\section{Computerized front-end}

The front-end of multimedia presentations contains 13 items suggested by Clarke (1993) taken from Ford's original 18-item Study Preference Questionnaire (SPQ) (Ford, 1985). This gave us an opportunity to test the effectiveness of Clarke's refinement made to the SPQ. Subjects rated each item on a Likert scale from 1 (strongly agree with the holistic statement) to 5 (strongly agree with the serial statement). Figure 1 shows the first screen of the front-end. The program then sums the scores for all questions. The maximum possible front-end score is 65; this would be obtained only if someone strongly agreed with all thirteen serial statements. Initially, the boundary between the two learning styles was set at 39.5 , the mid-point between highest and lowest possible scores. The front-end also asks for some more details of the users (name, age and sex) as well as their past computer experience and how they feel prior to operating certain presentations.

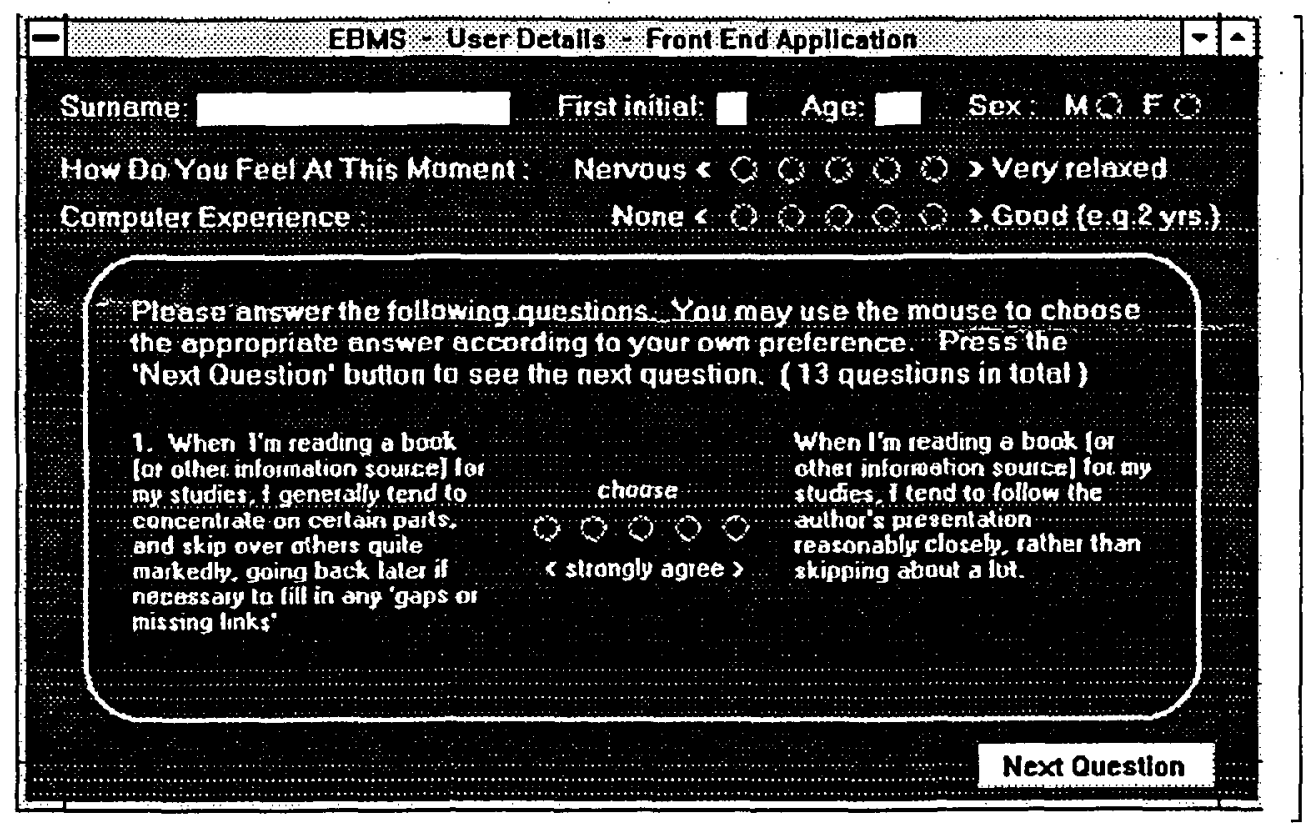

Figure 1: The Front-end

\section{Sample}

Fifty-eight first-year business studies undergraduates were involved in the study. Within the overall sample, thirty-four were female and twenty-four were male, reflecting the proportion of sexes in the Business School. All were volunteers and had all received at least two hours of training on operating personal computers and Microsoft's Windows. 


\section{Materials}

The materials used in the study were taken from the multimedia information presentations called the European Business Management School Visual Prospectus (EBMSVP) which was developed by one of the authors (MK) as a by-product of this research. The system includes a wide range of information about the European Business Management School and general information about Swansea and the University. It has three operation modes: self-running, menu driven, and fully interactive. As its name suggests, the selfrunning mode will run without interaction from users, but they may interrupt the system by pressing the Fast Forward paging button. The menu-driven mode allows users to choose what they want to see from the menus and then to page through the topic forward or backward by using appropriate buttons on the screen. The fully interactive mode increases the freedom of travelling around the system, and allows users to jump from menu to menu, and from one topic to another. They can also make use of the index facility quickly to look up any particular topic within the system. Such an index facility does not exist in the other two modes.

However, considering the testing time and the number of students who could be asked to take part in the project, the content of the testing materials has been made general. In the actual study, only two versions, menu driven and fully interactive, were used.

\section{Results}

Of the 58 students, 30 students (51.7\%) were classified as having a holistic learning style, and 28 students $(48.3 \%$ ) as having a serial learning style. They were assigned randomly to either the fully interactive version or the menu-driven version; 31 students $(53.4 \%)$ used the version which matched their learning styles, and 27 students (46.6\%) did not.

We applied a Kolmogorov-Smirnov Goodness of Fit Test to test the normality of both sets of data. The significant figures were $p=0.7717$ and $p=0.3201$, hence we had no evidence to say that both sets of data were not normally distributed. The mean performance scores for matched and mismatched groups were $11.58(\mathrm{SD}=3.69)$ and 10.22 $(\mathrm{SD}=3.62)$ respectively. Our initial assumption was that if we were using the improved version of the original 18 -item SPQ and we also used the correct boundary (i.e. 39.5 ) to divide students into ywo groups based on learning styles, we expected to see the mean score of the matched cases significantly greater than the mismatched cases. T-test for two independent samples was applied to compare their mean performances. Unfortunately, the test result was insignificant (at the $5 \%$ level), the one-tailed significance figure was $\mathrm{p}=0.082$. In other words, our 13-item front-end failed to detect and provide a suitable presentation for users who have different learning styles. Perhaps 39.5 was not the correct boundary. We reclassified all 58 cases with the mean front-end score 37.31, 29 of each were in the matching and mismatching categories. By comparing the mean scores of the two categories, we found a significant answer $(p=0.047)$. We also attempted to apply a single item - item 7 of the original SPQ - to define subjects' learning strategies as originally suggested by Clarke (1993). This gave 19 matched cases and 34 mismatched cases, and their mean performance scores were $10.63(\mathrm{SD}=4.06)$ and $10.79(\mathrm{SD}=3.46)$ respectively. (Note: the mismatched group has a slightly higher mean score). Five cases 
were ignored, since those subjects expressed no clear preference for either statement of the item 7.

A follow-up questionnaire was used to collect users' opinions on the front-end applied multimedia presentation, and answers were included in an exploratory factor analysis to assess the dimensionality of the learning style determination. This resulted in five factors, and crossloading situations also existed. After a reliability analysis, six items were removed. The remaining seven items proved to have a better degree of internal consistency, with reliability coefficient alpha value reaching 0.7086 from the initial alpha value 0.5799 (it has been suggested that a minimum alpha value of 0.90 should be achieved to have a reliable measure - Nunnally, 1967). We then carried out the analysis by assessing our subjects only with the seven items of the front-end. Disappointing results were again found. Although the average performance of the matching group (11.61) was higher than the average performance of the mismatching group (10.08), there was no evidence that this difference was significant statistically $(p=0,0595, p>0.05)$. There was one possible explanation for this failure to find significant differences on the students' study performances despite using the more reliable seven items of the front-end only. We might have a substantial number of students who were capable of performing equally well with different levels of interactivity of computer presentation. These were described by Pask (1976) as versatile learners, and their front-end scores would have dominated the central area of the distribution. Therefore, we excluded students from around the mean score of the distribution with the hope that these seven items of the front-end could efficiently detect extreme cases. Nine different factors were used to assess signifieant differences between matched and mismatched cases (see Table 1).

Table 1: Meanings of variables

\begin{tabular}{|c|c|}
\hline Variable Name & Meaning \\
\hline PERFORM & study performance \\
\hline ANXIETY1 & anxiety during the presentation \\
\hline EASYBUT & how easy to understand those on screen buttons \\
\hline EASYOP & how easy to operate the presentation \\
\hline LOST & sense of position of the presentation \\
\hline TEACHER & $\begin{array}{l}\text { how do they like multimedia presentations compared with conventional } \\
\text { lectures }\end{array}$ \\
\hline TEXTSYS & $\begin{array}{l}\text { how do they like multimedia presentations compared with text-based } \\
\text { computer presentations }\end{array}$ \\
\hline $\begin{array}{l}\text { OVERALL } \\
\text { TIME }\end{array}$ & $\begin{array}{l}\text { overall opinion on multimedia presentations } \\
\text { time spent on the presentation }\end{array}$ \\
\hline
\end{tabular}

At this stage, close to half of our overall sample, $48.28 \%$, were excluded from the centre of the front-end distribution. A significant difference between two groups' mean performance was found, and there were other significant results (see Table 2). 
Table 2: Comporison of different variables with different cut-off points

\begin{tabular}{|lcccc|}
\hline Variable & \multicolumn{3}{c|}{ Cut off Point } \\
\cline { 2 - 5 } & $\mathbf{2 0 . 7 9 3}$ & $\begin{array}{c}\text { Also Exclude } \\
\mathbf{2 0 , 2 1}\end{array}$ & $\begin{array}{c}\text { Also Exclude } \\
\mathbf{1 9 , 2 2}\end{array}$ & $\begin{array}{c}\text { Also Exclude } \\
\mathbf{1 8}, \mathbf{2 3}\end{array}$ \\
\hline PERFORM & $\mathbf{0 . 0 5 9 5}$ & $\mathbf{0 . 1 2 4 0}$ & $\mathbf{0 . 0 7 6 0}$ & $0.0465(0.0371)$ \\
ANXIETY1 & 0.2105 & 0.2100 & 0.2440 & $0.3700(0.4267)$ \\
EASYBUT & 0.1500 & 0.2645 & 0.4555 & $0.4760(0.5000)$ \\
EASYOP & 0.0050 & 0.0085 & 0.0135 & $0.0420(0.0389)$ \\
LOST & 0.0145 & 0.0605 & 0.0500 & $0.0200(0.0329)$ \\
OVERALL & 0.1160 & 0.1330 & 0.0570 & $0.0110(0.0196)$ \\
TIME & 0.0285 & 0.0550 & 0.0685 & $0.1700(0.1897)$ \\
TEACHER & 0.1350 & 0.2045 & 0.1400 & $0.1565(0.1285)$ \\
TEXTSYS & 0.3040 & 0.4595 & 0.1685 & $0.0685(0.0369)$ \\
\hline One-Tailed Significance: Parametric (Non-parametric) \\
Significant figures are italicized
\end{tabular}

\section{Conclusions}

Although we have found significant study performance differences between learning-style matching and mismatching groups using the seven items of the Study Preference Questionnaire, the result was strictly based on the 13-item Study Preference Questionnaire that Clarke suggested (Clarke, 1993). There were disagreements between both studies. Work should therefore be done once again on Ford's original 18-item Study Preference Questionnaire covering more variety of subject matters.

There were two possible factors which could affect our test results:

- the correct use of cut-off point of the front-end scores;

- the validity of the 13-item front-end.

However, the results suggest that the learners who really need guidance in selecting an appropriate navigation method in order to raise their interest in the material, i.e. those at the extremes of learning styles, can be helped.

\section{References}

Clarke, J. (1993), 'Cognitive style and computer-assisted learning: problems and a possible solution', Association for Learning Technology Journal, 1, 1, 47-59.

Entwistle, N. (1987), Understanding Classroom Learning, London, Hodder and Stoughton.

Ford, N. (1985), 'Learning styles and strategies of postgraduate students', British Journal of Educational Technology, 16, 1, 65-77. 
Kogan, N. (1971), 'Educational implications of cognitive styles', in Lesser, G.S. (ed), Psychology and Educational Practice, Illinois, Scott Foresman, 242-92.

Kolb, D.A. (1984), Experiential Learning: Experience as the Source of Learning and Development, Englewood Cliffs NJ, Prentice-Hall.

Marton, F. \& Säljö, R. (1976), 'On qualitative differences in learning: 1. outcome and process', British Journal of Educational Psychology, 46, 4-11.

Messick, S. (1970), 'The criterion problems in the evaluation of instruction: assessing possible, not just intended outcomes', in Wittrock, M.C. \& Wiley, D (eds), The Evaluation of Instruction: Issues and Problems, New York, Holt, Rinehart \& Winston.

Messick, S. (1976), Personality Consistency in Cognition and Creativity, Individuality in Learning, San Francisco, Jossey-Bass.

Nunnally, J.C. (1967), Psychometric Theory, New York, McGraw-Hill.

Pask, G. \& Scott, B.C.E. (1972), 'Learning strategies and individual competence', International Journal of Man-Machine Studies, 4, 217-53.

Pask, G. (1973), Educational Methods using Information about Individual Styles and Strategies of Learning, final report of the SSRC Project HR 1424/1 (2 volumes).

Pask, G. (1976), 'Style and strategies of learning', British Journal of Educational Psychology, 46, 128-48.

Patrick, J. \& Fitzgibbon, L. (1988), 'Structural displays as learning aids', International Journal of Man-Machine Studies, 28, 625-35.

Weinstein, C.E., Schulte, A.C. \& Cascallar (1983), The Learning and Strategies Inventory (LASSI), Initial Design and Development, Technical Report, US Army Research Institute for the Social and Behavioral Science, Alexandria, Virginia.

Witkin, H.A. (1976), 'Cognitive style in academic performance and in teacher-student relations', in Messick, S. et al. (eds), Individuality in Learning. San Francisco, Jossey-Bass. 